\title{
Mapuche y ranqueles en la Argentina: relatos sobre su pasado y presente
}

\section{Mapuche and Ranquel peoples in Argentina: tales of their past and present}

Aceptación: diciembre 2007.

Aprobación: marzo 2008.

Graciana Pérez Zavala'

\begin{abstract}
RESUMEN
En este artículo se plantea la reconstrucción de los relatos del pasado por parte de indigenas que viven en el territorio argentino, particularmente los mapuche y ranqueles. Para explicar estas variaciones en la interpretación del pasado por parte de las diferentes organizaciones indígenas, se examina la "Conquista del Desierto" (1878-1885), en tanto acontecimiento nodal en la estructuración de las relaciones interétnicas actuales en Argentina. En primer lugar, se sintetizan varios elementos de la historia de los indigenas de Pampa y Patagonia en los años previos a su sometimiento. Posteriormente, se describen los acontecimientos ligados a la "Conquista del Desierto", teniendo en cuenta al Estado argentino y a las diferentes "tribus". Luego, se caracteriza la situación de los indigenas después de 1885, y para finalizar, se analizan los relatos de los mapuche y ranqueles contemporáneos en el marco de su resurgimiento como pueblos preexistentes al Estado Nacional argentino.
\end{abstract}

Palabras clave: Conquista del desierto, construcción de identidad, relatos etnohistóricos, mapuchel ranqueles.

\begin{abstract}
The aim of this article is the reconstruction of tales of the past by indigenous peoples living in Argentinean territory, particularly of the Mapuche and Ranquel ethnic groups. To explain these variations in the interpretation of the past by different indigenous organizations we examine the "Conquest of the Desert" (1878-1885) as a nodal event in the structuring of the inter-ethnic relations which exist today in Argentina. In the first place various elements of the history of the indigenous peoples of the Pampa and Patagonia in the years previous to their subjugation are summarised. Subsequently the events linked to the "Conquest of the Desert" are recounted, both from the perspective of the State of Argentina and that of the different "tribes". Next the situation of the indigenous peoples after 1885 is described; and finally the tales of contemporary Mapuche and Ranquel communities are retold in the framework of their resurgence as peoples which pre-existed the Nation-State of Argentina.
\end{abstract}

Key words: Conquest of the desert, identity construction, ethno-historical tales, Mapuche/Ranquel.

Magister en Antropología, Universidad Nacional de Río Cuarto y Universidad Nacional de Villa Maria, Argentina. gracianapz@yahoo.com

DOI: 10.7770/CUHSO-V16N2-ART279 
En la Argentina muchos pobladores que en las décadas anteriores negaban su ascendencia indígena hoy la reconocen. Este es el caso de los ranqueles y mapuche de las Provincias de La Pampa y Neuquén, que están fortaleciendo su identidad y su accionar frente al Estado argentino a partir de la reconstrucción de su pasado. Sin embargo, esta reelaboración de su historia no es uniforme, en tanto los relatos presentan variaciones según las identificaciones étnicas de sus narradores, como también de acuerdo a su situación socioeconómica y generacional. En trabajos anteriores advertimos que la historia que están elaborando los dirigentes indigenas, especialmente los residentes en las ciudades, encuentra su sustento tanto en la historia oficial como en la memoria de los "antiguos". La misma resignifica el relato nacional, en lo que respecta a aquellos acontecimientos que dan cuenta de la imposición estatal sobre los indigenas de Pampa y Patagonia y, por tanto, se constituye en un instrumento de lucha política (Pérez Zavala y Tamagnini, 2005).

En este escrito procuraremos avanzar en esta temática buscando identificar las causas por las cuales existen notorios contrastes en la interpretación que hacen de su pasado quienes hoy se definen como mapuche $y$ ranqueles. Los primeros, los habitantes del Neuquén, consideran que antes de la "Conquista del Desierto" eran "un pueblo libre" que habitaba en un "espacio territorial" que comprendía parte de "la provincia de Buenos Aires, del sur de Córdoba, el sur de San Luis, Mendoza y lo que es Chile, en la parte de Santiago hasta el Chiloé". Por su parte, los ranqueles contemporáneos destacan que su presencia en la pampa central y su interacción sobre el sur de las fronteras de San Luis, Córdoba y Santa Fe es previa al ingreso de los mapuche en las tierras de orientales de la cordillera de los Andes. En consecuencia, los ranqueles postulan que son diferentes a los mapuche y que los reclamos de estos son infundados. En respuesta a esta visión, los dirigentes neuquinos remarcan que si bien los libros de historia oficial caracterizan como pueblos diferentes a los "pehuenche", "huiliche", "picunche", "ranqueles", "araucanos" y "mapuche", todos eran "un mismo pueblo" que poseían una misma organización "mile. naria"2.

Para explicar esta variación en la interpretación del pasado por parte de las diferentes organizaciones indígenas, examinaremos la "Conquista del Desierto" (1878-1885) en tanto acontecimiento nodal en la estructuración de las relaciones interétnicas e intraétnicas. Como advierte Delrio (2005), las campañas militares y el cruce de la cordillera forman parte de los tópicos de la mayoria de los ngitram sobre los orígenes de las actuales comunidades indígenas, en razón de que representan el momento de la desestructuración y la imposición de nuevas relaciones sociales. Por ello, desde una perspectiva que considera la "politica del pasado" a la luz de aquellos acontecimientos históricos específicos ligados con el gobierno social y las luchas derivadas por su control-mantenimiento (Rocchietti, 1998), sostenemos que este hecho condensó los complejos procesos de violencia interétnica gestados a lo largo de varios siglos entre indigenas y cristianos y simultáneamente dio lugar a una nueva configuración sociopolítica bajo la cual los primeros, además de quedar sujetos al Estado Nacional argentino, debieron redefinir sus identificaciones étnicas. Específicamente, planteamos que durante las expediciones nacionales sobre los territorios de Pampa y Patagonia cristalizaron las diferencias en la política de las "tribus" que habitaban tales espacios pese a la emergencia de ciertos proyectos de resistencia conjunta ante la avanzada militar. Los derivados de esta política dual de los indígenas, junto a los procesos de reorganización territorial y politica que implementó el Estado Nacional para con estos una vez finalizada la "Conquista", están presentes bajo una suerte de efecto

Relatos obtenidos durante trabajos de campo en la ruca de la Confederación Mapuche Neuquina, sita en Neuquén Capital y en las comunidades rurales Lonco Purrán y Paraje Piedra Trompul, en el marco de "Viajes de Estudio a las Comunidades Mapuche de la Provincia de Neuquén", Proyecto PIIMEG, Universidad Nacional de Río Cuarto (2004- 2005). Las entrevistas a dirigentes y miembros de la comunidad ranquel de la Provincia de La Pampa fueron efectuadas en las ciudades de Río Cuarto, Santa Rosa y Telén (2004-2007). 
acumulativo en los conflictos y dilemas que hoy poseen las organizaciones mapuche y ranqueles.

En este escrito, primero reseñamos algunos elementos de la historia de los indígenas de Pampa y Patagonia en los años previos a su sometimiento. Luego, describimos los sucesos ligados a la "Conquista del Desierto" teniendo en cuenta, por una parte, la política del Estado argentino y, por otra, la de las diferentes "tribus". Posteriormente caracterizamos, someramente, la situación de los indígenas después de 1885 y finalmente analizamos los relatos de los mapuche y ranqueles contemporáneos en el marco de su resurgimiento como pueblos preexistentes al Estado Nacional argentino.

Los indigenas de Pampa y Norpatagonia en la segunda mitad del siglo XIX

Varios autores remarcaron la necesidad de estudiar conjuntamente a los indigenas situados en la Araucania (Chile) y en Pampa y Patagonia (Argentina) dadas las vinculaciones que durante los siglos XVIII y XIX existieron entre estos. Si bien ya desde la segunda mitad del siglo XVIII existía una fuerte relación entre los habitantes de tales espacios, este proceso se acentuó cuando se consolidaron las fronteras del territorio indígena y se estabilizó la línea militar en el antiguo Virreinato del Río de la Plata. A su vez, para las primeras décadas del siglo XIX, la economía indígena se había diversificado, según los distintos recursos y posibilidades del medio, de modo que los grupos nativos complementaban entre sí al tiempo que profundizaban su dependencia respecto de la sociedad cristiana. Ello era así porque los indígenas fueron quedando integrados en los circuitos mercantiles chilenos y argentinos y, a través de estos, en los mercados mundiales en formación (León Solís, 1982; Bechis, 1984; Mandrini, 1984; Palermo, 1986; Pinto Rodríguez, 1996; Foerster y Vergara 1996). Simultáneamente, estas relaciones entre indigenas de diferentes regiones habrian dado entidad, en términos de Martha Bechis (1999), al "área arauco-pampeana-norpata- gónica", la cual se materializaba en cierta unidad cultural y social entre un lado y otro de la cordillera.

Esta estrecha relación en los aspectos económicos, culturales y sociales no necesariamente se hizo visible en las organizaciones politicas de Pampa, Norpatagonia y Araucanía $^{3}$. Más allá de las discusiones en los investigadores en torno a su caracterización política, existe cierta coincidencia en el hecho de que estas no actuaban en forma unificada ante los respectivos gobiernos chileno y argentino. Las rivalidades entre caciques, las antiguas disputas intraétnicas y los conflictos interétnicos fueron algunos de los elementos que impidieron gran parte de los proyectos tendientes a la unificación. Bechis (1999) sostiene que la dinámica sociopolítica de los indígenas del "área araucopampeana-norpatagónica" estaba sujeta a continuos procesos de fusión y fisión que involucraban a agrupaciones, caciques, capitanejos, mocetones y chinas. Esta flexibilidad habria repercutido en la lucha interétnica haciendo que cada unidad política desplegara y modificara sus alianzas con los cristianos y con las otras unidades indigenas ante beneficios coyunturales o de largo plazo. Asi, una misma agrupación podía ser considerada por los cristianos simultáneamente como enemiga, aliada y amiga según los acontecimientos históricos que demarcaban el accionar politico de las partes. Del mismo modo, mientras algunos caciques eran agasajados como amigos y aliados, otros eran reprendidos en razón de su hostilidad (Ratto, 1994; Villar y Jiménez, 2006).

Si bien en el presente es frecuente la utilización de denominación de mapuche para los antiguos habitantes de Pampa y Norpatagonia, la documentación de la segunda mitad del siglo XIX los designa de otro modo. Mientras los indígenas ubicados cerca de las Salinas Grandes son definidos como salineros o indios de Calfucurá o "chilenos", aquellos situados en el monte de caldén y los medanales (actual Provincia de La Pampa) son nombrados como ranqueles. Por su parte, los

3 Por cuestiones de espacio aqui no se examina la problemática política de los indigenas de ta Araucanía. 
indígenas emplazados en cercanías de la cordillera recibían los calificativos de pehuenches, huiliches y manzaneros, dependiendo estas categorías de sus localizaciones y procesos de etnogénesis. Para mediados del siglo $\mathrm{XIX}$, salineros, ranqueles y manzaneros eran las principales agrupaciones indigenas del este de la cordillera. Los primeros provenían de la Araucanía y, liderados por Calfucurá, se instalaron en las Salinas Grandes en la década de 1830 bajo el amparo de Juan Manuel de Rosas. Luego de la derrota de este último, Calfucurá, a través de los ranqueles, se alió a la Confederación Argentina para posteriormente, en las décadas del 60 y 70 , asumir estrategias de alianza y oposición según los acuerdos con los demás caciques de la región y con los gobiernos provinciales y nacionales. Los ranqueles, en cambio, asentados en la pampa central desde el siglo XVII, resistieron las expediciones del Gobernador porteño en pos de defender su autonomía. En la década de 1850 colaboraron con el general Urquiza, pero en los años 60 adhirieron a los líderes de las montoneras que se enfrentaban al Gobierno Nacional guiado por Buenos Aires. Una vez que este último se impuso, los ranqueles sostuvieron relaciones diplomáticas con el Gobierno Nacional, las cuales quedaron plasmadas en tratados de paz (1870, 1872 y 1878). El cacique Chocorí también fue afectado por las campañas punitivas de Rosas, logrando luego de ellas ser reconocido como un cacique de prestigio y sentar las bases para la conformación de una identidad manzanera que, organizada por Valentín Sayhueque (su sucesor), se destacó en los años 60 y 70 debido a sus estrechos vínculos con el Gobierno Nacional. Los manzaneros impulsaron cierta estrategia la "integración", en tanto Sayhueque se definía como "indio argentino" y avalaba las campañas punitivas del Gobierno Nacional para con los salineros guiados por Namuncurá. Asimismo, entre los pehuenches se destacaba el cacique Purrán, que efectuaba, simultáneamente, tratos con los gobiernos argentino y chileno (Mandrini y Ortelli, 1993; De Jong, 2002; Vezub, 2006; Tamagnini y Pérez Zavala, 2004; Varela y Manara, 2006). El "área arauco-pampeana-norpatagónica" se desdibujó hacia 1880 , en el marco de la "Pacificación de la Araucania" y la "Conquista del Desierto".
La política nacional: "Conquista del Desierto"

En la década de 1870 el Gobierno Nacional argentino debatió la conveniencia de reducir a los indígenas o correrlos hacia los ríos Negro y Neuquén (según lo disponía la Ley $\mathrm{N}^{\circ} 215$ de 1867). Esta discusión se plasmó en la aplicación conjunta de proyectos bélicos, diplomáticos y colonizadores. En 1875 el Ministro de Guerra y Marina, Adolfo Alsina, planteó ganar tierras por medio de líneas sucesivas, siendo su meta principal la ocupación de Carhué (sitio con aguadas y buenos pastos próximos a las Salinas Grandes). Sin bien los malones de Namuncurá (hijo de Calfucurá) impidieron la concreción de gran parte de los objetivos militares, hacia mediados de 1876 las fuerzas nacionales avanzaron la línea instalando bases en Italó, Trenque Lauquen, Guamini, Caruhé y Puán. El plan de Alsina no fue valorado positivamente por muchos jefes militares, pero los indígenas perdieron varias batallas y no pudieron impedir el avance nacional. Así, $\mathrm{Na}$ muncurá debió trasladar sus toldos de Chilihué hasta el valle Argentino y Tratú Lauquen (Whalter, 1980).

Alsina murió en 1877, siendo reemplazado por el general Julio Argentino Roca. El nuevo ministro propuso realizar una campaña en gran escala contra los indigenas, la cual fue avalada, en octubre de 1878 , con la Ley $\mathrm{N}^{\circ}$ 947. En la perspectiva de Navarro Floria (2005), en sintonía con su proyecto de Conquista de la Pampa, el ministro Roca fue construyendo un discurso historiográfico por el cual él mismo se reivindicaba como protagonista y continuador de una política militar conquistadora de larga data. Si bien el general Roca retomaba el camino iniciado por Alsina en 1875 -sus operaciones se organizaban a partir de Carhué- y sus metas - alcanzar el río Negro-, en el plano discursivo y en la polémica que antecedió a la campaña de 1879 , el nuevo ministro trató de distanciarse de la estrategia de su antecesor, situándola dentro de las políticas defensivas.

En octubre de 1878 se iniciaron las expediciones "ligeras" sobre las tolderías, las cuales se extendieron hasta los primeros meses de 1879. Estas partieron de los fuertes de 
Patagones, Puán, Caruhé, Guaminí, TrenqueLauquen, Italó, Río Cuarto, Villa Mercedes, Patagones y San Rafael, y dieron por resultado la desorganización generalizada de las "tribus" y la captura de varios caciques. Terminada esta primera fase, la "Conquista del Desierto" se completó en 1879 con la marcha triunfal del ministro de Guerra y Marina que, al frente del ejército expedicionario, enarboló el 25 de mayo la bandera nacional en las márgenes del río Negro. Con este acto se simbolizaba la efectiva ocupación de las tierras de Pampa y Patagonia. Entre el 1 de abril y el 2 de mayo de 1879 habían partido hacia el sur cinco columnas de expedicionarios militares que lograron tal avance nacional. La ocupación definitiva de la Patagonia se completó tiempo después con las expediciones del general Villegas al lago Nahuel Huapi (1881) y a los Andes (1882). Estas avanzaron sobre "los indios del Triángulo" - como se denominaba el Neuquén-y establecieron un conjunto de fuertes y fortines que permitieron quebrar las relaciones transcordilleranas de la población indígena. Finalmente las campañas de 1884 y 1885 lograron cautivar a los caciques Icanayal, Foyel y Sayhueque. Con la rendición del último cacique "rebelde", terminaba oficialmente la guerra con los indigenas del sur (Durán, 2004; Mases, 2002).

La política de los indigenas de Pampa y Norpatagonia ante la "gran invasión"

Los indigenas de Pampa y Norpatagonia conocian los planes nacionales de avance hasta los ríos Negro y Neuquén. Por ello, en algunas coyunturas, buscaron conformar una alianza en pos de resistir en forma coordinada. Estos planes tuvieron vigencia antes, durante y después de la "Conquista del Desierto", pero no encontraron los resultados esperados. Cada "tribu" desarrolló su propia política, lo cual terminó favoreciendo el proyecto nacional.

Un artículo periodístico de junio de 1877 afirmaba: "Hace tiempo se viene anun- ciando una grande invasión á esta provincia por los indios Pehuenches. En parlamentos que han tenido en los valles de Neuquen, precedidos por el cacique Puran, el más poderoso de toda esa region, han resuelto atacar á Mendoza y proteger á los Pampas en su Guerra contra Buenos Aires. Una grande agitacion se nota en toda la Pampa desde Salinas y Lebucó a los Andes. [...] Los Ranqueles estan asediados constantemente por mensageros de Namucurá; y de los caciques chilenos, para que rompan la paz con los cristianos. La conducta de Mariano media ambigua, desde algun tiempo á esta parte, no hace recelar que al fin tenga que ceder a las sugestiones tan poderosas. Parlamentos de Salinas recorren tambien los Andes en demanda de ausilios. Hasta los Huiliches, habitantes de los márgenes del Limay, dicen tomarán parte de la Santa Cruzada contra los cristianos" 4 .

Los parlamentos entre las "tribus" tenían por meta definir la política indigena respecto de los proyectos nacionales. Si bien la propuesta del "gran malón" ofrecía la posibilidad de demostrar la fuerza bélica indigena en pos de impedir el progresivo avance cristiano hacia el sur, no todos los caciques consideraron esta posibilidad. Los ranqueles Epumer Rosas y Manuel Baigorrita prefirieron sostener el tratado de 1872. A su vez, los salineros impulsaron una politica dual: buscaron llegar a un acuerdo mediante el auxilio de los ranqueles y, simultáneamente, mantuvieron lazos con los caciques que optaban por enfrentarse al Gobierno Nacional.

En el período 1877-1878 los ranqueles intentaron acercar a los salineros al Gobierno Nacional dado que, por entonces, los jefes militares rechazaban las comitivas de Namuncurá que viajaban a Buenos Aires pidiendo la paz y una compensación por la ocupación nacional de los campos de Puán, Carhué y Guaminí. Sin embargo, el general Julio Roca denegaba las peticiones salineras alegando que Namuncurá no había "mandado persona de representa-

4 Archivo Histórico del Convento de San Francisco, Río Cuarto (AHCSF). Año 1877. Doc. № 742 . Diario "La voz de Rio Cuarto". 22/06/1877. En: Tamagnini, 1995:229. 
cion, que manda pedir y que mientras tanto prepara invasiones" 5 .

Mientras los emisarios salineros eran rechazados, el Gobierno Nacional concretó en Buenos Aires, en julio de 1878, un tratado de paz con los ranqueles. Este reviste un valor particular, en tanto fue el último que realizaron los indígenas de Pampa y Patagonia.

En momentos en que los ranqueles concretaban la paz, el capitanejo Juan Romero (sito en el río Negro) ponía en conocimiento a Manuel Namuncurá de los proyectos nacionales de "quitarles sus campos" y de tomarlos prisioneros. Le informaba que en Chile se sucedían los mismos "enredos" entre indígenas y cristianos y que los caciques Nancucheo y Sayhueque ofrecian su colaboración para resistir. Purrán y los caciques chilenos proponían concentrarse en el río Colorado ${ }^{6}$.

Namuncurá consideró las propuestas de los manzaneros y preparó a su gente para el combate, aunque paralelamente buscó un tratado con el Gobierno. Para desarrollar esta última política recurrió a Epumer. Un mes después, Bernardo Namuncurá le comentaba al coronel Wintter que la gran junta de caciques quería llegar a un acuerdo de paz y que por intermedio de los jefes militares y de los misioneros de la frontera cordobesa procuraban que el presidente Avellaneda les concediera "los arreglos de paz con el Superior Gob. Nacional"

La cooperación entre ranqueles y salineros ya no alcanzaba para contrarrestar los planes del Gobierno Nacional. Tal como estaba proyectado, en esos días comenzaron las "campañas de ablandamiento". Tanto los indígenas aliados como enemigos al Gobierno fueron objeto de estas persecuciones. Los caciques Epumer y Pincén, entre otros, fueron tomados prisioneros y trasladados a la isla Martín García. Los que lograron escapar iniciaron su peregrinaje hacia la cordillera de los Andes en busca del auxilio de los lanceros de aquel espacio. Sin embargo, cada "tribu" fue quedando librada a su suerte.

En julio de 1879, en consonancia con la toma de posesión del "desierto" por parte de las fuerzas nacionales, Sayhueque, Namuncurá y Baigorrita impulsaban sus últimas acciones como caciques soberanos. Sayhueque daba cuenta a los jefes militares de Chos-Malal sobre los padecimientos que sufrían sus indios con motivo de la presencia de efectivos nacionales en sus tierras. Advertía que el general Roca y el coronel Barros le habían ofrecido amistad y habían sido "gene rosos" con él y su "gente". Pero que dichas autoridades no habían "reflexionado" con los caciques Namuncurá, Reumay y Guenpunilla en razón de que no eran "criollos y nativos de esas pampas, si no [que] tienen su domicilio y autoridad en los desiertos donde vive actualmente Renquecura" ${ }^{8}$. Por entonces, Namuncurá cruzaba la cordillera de los Andes buscando refugio en la Araucanía. A su vez, en Neuquén, después de varios meses de persecución, moría el cacique Baigorrita. Según Pío Bentivoglio, capellán de la $3^{\text {ra }}$ División, este había respondido a los emisarios nacionales: "sé muy bien que estoy rodeado por

s AHCSF, Año 1878. Doc. № 888. Rte: Bernardo Namuncurá a Nelsón Moreno. Trunaque de Salinas, 19/06/1878. En: Tamagnini, 1995:46. Este tema también aparece en otra correspondencia de la época, para ello véase: Archivo Estanislao Zeballos (AEZ). Rte: Manuel Namuncurá a Nicolás Levalle. Salinas Grandes, 5/12/1877; Rte: Manuel Namuncurá a Adol fo Alsina. Salinas Grandes, 5/12/1877; Marcos Donati a Bernardo Namuncurá. Villa Mercedes, 21/03/1878. En: Durán, 2006:410-415; 168-169. AHCSF. Año 1878. Doc. N 832. Rte: Manuel Namuncurá a Marcos Donati. Salinas Grandes en Trunaqué, 5/02/1878; Doc. N ${ }^{\circ} 887$. Rte: Federico Aneiros a Marcos Donati. Buenos Aires, 11/06/1878. En: Tamagnini, 1995:41-42;250.

6 AEZ. Rte: Juan Romero a Manuel Namuncurá. Rio Negro, 25/07/1878. En: Durán, 2006:201-202.

7 AEZ. Rte: Lorenzo Wintter a Bernardo Namuncurá. 08/1878. En: Durán, 2006:169. Varias cartas guardadas en el AHCSF también dan cuenta de estas negociaciones: Doc. № 895. Rte: Epumer Rosas a Marcos Donati. Lebucó, 4/07/1878; Doc. $N^{\circ}$ 934b. Rte: Albarito Reumay a Marcos Donati. Trunaque de Salinas, 20/09/1878; Doc. $N^{\circ} 935$. Rte: Manuel Na muncurá a Marcos Donati. Trunaque de Salinas, 20/09/1878. Doc. № 939. Rte: Epumer Rosas a Marcos Donati. Lebucó, 9/10/1878. En: Tamagnini, 1995:47; 49-51.

8 AEZ. Correspondencia de caciques del Río Negro y del Neuquén. Rte: Valentín Sayhueque a Superiores del campamento de Chos-Malal. Río Calvufo, 3/07/1878. En: Durán, 2006:202-203. 
todas partes, con todo no me rindo. Tenga el Comandante paciencia hasta que se hayan incorporado los Peguenches que vienen y voy á encontrar y nos veremos las cosas" . Sin embargo, por entonces, "muchos indios de Baigorrita, de Pincen y demás tribus mezclados, a pie y en la mayor miseria han caido en poder de las fuerzas de Uriburu. Andan como locos estos desgraciados. Por todas partes se encuentran con fuerzas. Ya no hacen ademán, no digo de pelear, ni de disparar siquiera $^{10}$.

Varios de los caciques y capitanejos tomados prisioneros o sometidos voluntariamente fueron incorporados a las fuerzas expedicionarias nacionales participando así en la persecución de quienes seguían huyendo. El cacique Bartolomé Curruhuinca es un ejemplo de ello. Este, en diciembre de 1882, fue integrado a la Segunda División que lideraba el coronel Villegas. Según los partes militares, Curruhuinca y los indios que lo seguian mostraron un comportamiento adecuado por lo que los jefes militares lo premiaron con raciones (Fernández, 1999; Kalinsky y Cañete, 2000). La militarización de los indígenas reducidos y el resentimiento que esto generaba entre los que continuaban huyendo acentuaron las diferencias intraétnicas.

Los indígenas de Pampa y Patagonia después de las expediciones militares

Después de las expediciones militares el destino de indios amigos, aliados y enemigos fue bastante similar. Muchos murieron en combate o a causa de las epidemias de viruela. Los sobrevivientes fueron destinados a la isla Martín García, a la zafra en Tucumán, al Museo de La Plata, al Ejército, a la Marina o al servicio doméstico en el seno de familias pudientes de Buenos Aires, Rosario y Córdoba. Algunos contingentes fueron incorporados como peones en las estancias que estaban surgiendo en Pampa y Patagonia (luego de la ocupación nacional del "desierto" el Gobierno entregó tierras a los militares participantes en las expediciones punitivas como asi también a empresarios que habían colaborado con su financiación). Asimismo, hacia fines de la década del 80 y en los comienzos de la siguiente, algunos caciques y sus seguidores recibieron, por decretos presidenciales, tierras fiscales: en 1888 el cacique Curruhuinca y sus parcialidades fueron autorizados a instalarse por diez años en el paraje Chapelco (Provincia de Neuquén); en 1894 se le concedió al cacique Namuncurá ocho leguas de campo sobre la margen derecha del río Negro, en el paraje denominado Chimpay; el año siguiente, Sayhueque recibió tierras en la actual Provincia de Chubut. Por su parte, entre 1898 y 1890 los ranqueles Luis Baigorria, Cabral y Santos Morales y sus "tribus" fueron radicados en Colonia Mitre, actual Provincia de La Pampa (Mases, 2002).

La distribución de tierras que efectuó el Gobierno Nacional a los caciques que mantenían a su cargo a cierto número de seguidores luego de las expediciones militares, reprodujo, parcialmente, las estructuras tradicionales, es decir, los caciques siguieron siendo los representantes de sus "tribus" ante el Estado argentino (Delrio, 2005). Además, en algunos casos tales caciques fueron localizados en tierras cercanas a las de sus antiguos emplazamientos (Luis Baigorria y Curruhuinca, entre otros). Sin embargo, simultáneamente, se produjo un proceso de reconfiguración étnica según el cual ciertos caciques, por ejemplo Namuncurá, fueron instalados en espacios totalmente alejados de los que poseían antes de 1878. Estos debieron interactuar con los indigenas que circundaban esas regiones, especialmente con partidas de distinto origen (ranqueles, salineras, pehuenches, etc.) que en el marco de las persecuciones militares fueron conformando nuevas "tribus". Las tierras centrales del Neuquén fueron objeto de estas ocupaciones.

\footnotetext{
AHCSF. Año 1879. Doc. $N^{*}$ 1030. Rte: Pio Bentivoglio a Marcos Donati. Pitrílauquen, 13/06/1879. En: Tamagnini, 1995:271.

10 Carta de Julio. A. Roca a su hermano Ataliva Roca, 22/06/1879. En: Luna, 1989:466.
} 


\section{Revista CUHSO volumen $16 \mathrm{~N}^{\circ} 2$}

Mapuche y ranqueles un siglo después de la "Conquista del Desierto"

Para comenzar esta sección creemos pertinente rescatar dos relatos que, pese a ser distantes en el tiempo, tienen la particularidad de evidenciar cómo la "Conquista del Desierto" y su recuerdo perduraron en estas poblaciones sometidas. El primero pertenece a Alberto Huichulef, quien en 1967 contó lo siguiente "[...] Namuncurá sufrió mucho, pues no tenía ayuda en Chile. Hicieron un consejo de mapuches argentinos y acordaron ir a pedirle al Presidente Roca que dejara volver a Namuncurá a su patria. Asi lo hicieron. Fueron a Buenos Aires y hablaron con el Presidente y éste lo consistió. Les dijo que Namuncurá podía volver sin temor [que] las tierras que el gobierno dio a tu padre ya se vendieron. No tienes nada, asi que busca otro lugar y donde lo encuentres te puedes instalar. Namuncurá, buscando otro lugar donde instalarse, llegó a Junín, al río San Ignacio, y allí se fueron a vivir, y recuperó sus campos" (En: Calvo, 1990:97-100).

En el años 2004, Petrona, de la comunidad rural Lonco Purrán, nos dijo: "la abuela de mi finada madre decía que conoció cuando hubo guerra viste [...] que era muy feo, que era muy feo pero no cuando llevaban toda la gente en una ciudad decía, para tenerlo todo para cuando empezaban a pelear así y después la gente que quedaba por ahi si no hay algo que comer y tenía que comer pasto, pasto, y después una caña que sale de la cordillera, dice que esa la pelaban y la comian a eso, porque no habia que comer, porque hasta que no se cuanto tiempo estuvo la guerra. Mi papá no contaba nada, de eso nada, nunca me habló de que aiga mapuche o comunidad [pero] era paisano, hablaba en paisano".

Las narrativas sobre la "Conquista" cuentan "la historia de los padecimientos de los abuelos, historia que es también la de los padecimientos del presente" (Delrio, 2005:40). En estos relatos es notable el modo en que las generaciones posteriores a las expediciones militares recordaron cotidianamente el sufrimiento de sus padres y abuelos con motivo de la guerra, el hambre y el frío de la huida, pese a que paralelamente buscaron ocultar aquellos rasgos que los definían como indígenas. Esta posición negativa respecto de sus orígenes comenzó a transformarse en las últimas tres décadas en el marco de nuevos procesos de avance territorial sobre los "paisanos" de Neuquén y de La Pampa.

Germán Canhué, "descendiente de los Rankülches del Norte", recuerda que en 1970 mientras vivía en Buenos Aires, conoció los desalojos que se sucedían en Colonia Emilio Mitre con motivo de un decreto de la Provincia de La Pampa que sostenía que "la tierra no es para el que la tiene ni para quien la trabaja sino para quien mejor puede trabajarla". Ante ello, "interpretó que el blanco los sigue viendo como indios, que la causa sigue vigente". A su iniciativa se sumaron las $4^{\text {as }} y$ $5^{\text {as }}$ generaciones de descendientes de los ranqueles sometidos por el ejército que empezaron a reconocer que "seguian siendo indios" y que "unidos" podrían encabezar una nueva "rebelión", la cual se sustenta en el Derecho. De la mano de esta meta, los ranqueles, reconocidos oficialmente por el Estado argentino, lograron la restitución de los restos del cacique Mariano Rosas (guardados en el Museo de la Plata), de la aplicación de algunos proyecto de educación bilingües, al tiempo que continúan reclamando la devolución de tierras.

De igual modo, según los testimonios de dirigentes mapuche hace "30 años" se constituyó la "Confederación Mapuche Neuquina" a partir de la iniciativa de la Iglesia Católica, representada en el obispo Jaime de Nevares, y el aval del "Movimiento Popular Neuquino", partido político de la Provincia. Ambas instituciones buscaron nuclear a las diferentes comunidades rurales del Neuquén que, pese a la negativa de sus propios moradores, eran de origen indígena. Con el tiempo estos y en particular los pobladores de las ciudades neuquinas comenzaron a valorar positivamente su pasado étnico, iniciando así un proceso de búsqueda de autonomía politica basado en la identidad mapuche. En este contexto, los actuales lideres de la Confederación se definen como "anti MPN" a la vez que están distanciados de la Iglesia Católica.

Los reclamos de los mapuche y de los ranqueles encuentran su fundamento en los acontecimientos del pasado, los cuales son interpretados tanto a partir de lo que "cuen- 
tan los antiguos" como de la perspectiva impuesta por el Estado argentino a lo largo del siglo XX. Sus historias remarcan las acciones indígenas de resistencia como también las distintas identificaciones étnicas antes y después de la "Conquista del Desierto". En este sentido, los dirigentes ranqueles están buscando documentación en archivos históricos e investigaciones científicas que den cuenta de su existencia como "nación" previa al surgimiento de la Argentina y, simultáneamente, diferente de los mapuche. Así, los ranqueles plantean que es necesario que se conozca la "verdadera historia", dado que si bien algunos investigadores "escriben que "mapuches", entre otros pueblos, estuvieron en el Cabildo de Buenos Aires ofreciendo sus servicios", ello sería erróneo porque los documentos de época no mencionan a los "mapuche". Para sostener este argumento los ranqueles contemporáneos agregan que durante el siglo XIX la "nación Mamülche" y/o los "ranqueles" concretaron una serie de tratados de paz con los distintos gobiernos argentinos, gracias a los cuales fueron reconocidos como naciones independientes. Además, recuerdan que quienes hoy se definen como mapuche lo hicieron bajo la presión de funcionarios argentinos y "extranjeros" que reunidos en "un Congreso en San Martín de los Andes" en 1961 los nominaron de ese modo.

Esta mirada sobre el pasado de los ranqueles se opone a la de los mapuche de la Confederación Neuquina. Una de sus dirigentes, en diciembre de 2004, nos narró la historia de su pueblo tomando como base cuatro mapas a partir de los cuales identificó varias etapas en las relaciones interétnicas en el período 1800-2004. Reseño así el proceso por el cual se "fue dando la reducción territorial" indigena, que hizo que los mapuche dejaran de ser "un pueblo libre". Esto último ocurrió en "1879 cuando la frontera se fue corriendo, se veia que esta frontera había avanzado, seguía avanzando sobre el territorio mapuche. Entonces, en 1879 hablamos de la "campaña del desierto", en manos del prócer Julio Argentino Roca que violando la ley del Congreso Nacional, la 1.947 que establecía que tenía que bajar la frontera hasta el río Limay y el río Neuquén, avanzó sobre todo Neuquén". Según su explicación, luego de este acontecimiento los mapuche perdieron su "autonomía política" y el dominio de sus tierras que se extendían en ambos lados de la cordillera de los Andes. Asi, muchos mapuche fueron obligados a vivir en la ciudad pero, paradójicamente, "hoy, una de las luchas más fuertes del pueblo mapuche en las provincias sale desde las ciudades". Desde su perspectiva, en ellas se materializa el último momento de la historia de los mapuche, basado en una realidad en la que es preciso "concientizar" a los pobladores rurales de su identidad y acordar con los "hermanos que niegan ser mapuche" como consecuencia de que han interiorizado la historia oficial que los situó como pueblos rivales. Las declaraciones finales de los dirigentes mapuche no son de menor importancia en razón de que tanto estos como los ranqueles se asumen como herederos legítimos de las tierras de la pampa central. Pese a que en ambos casos la reconstrucción del pasado tiene una misma meta (obtención de tierras y reconocimiento de existencia política previa al Estado argentino), su diferente interpretación los posiciona en campos opuestos. Este distanciamiento entre dirigentes mapuche y ranqueles es visible en la política que estos despliegan para con los Gobiernos Nacional y Provinciales.

Entre las cerca de 50 comunidades rurales y urbanas que conforman la Confederación Mapuche Neuquina también existen ciertas disidencias. Estas tienen varias causales, siendo algunas de ellas la heterogeneidad de sus orígenes y la relación de alianza/oposición con el Gobierno Neuquino. Algunas son "antiguas" y están ligadas a la entrega de tierras que hizo el Gobierno luego de la "Conquista del Desierto". La comunidad Curruhuinca, situada en las cercanias de San Martín de los Andes, se inscribe en este conjunto. Sus moradores sufrieron a mediados del siglo XX la intromisión de Parques Nacionales y actualmente hacen frente a empresas forestales y a proyecto de desarrollo turístico. Sin embargo, aun cuando muestran su recelo respecto del Gobierno Provincial no avalan la politica de los dirigentes mapuche de Neuquén Capital porque consideran que estos desconocen sus verdaderas problemáticas. Diferente es el caso de otras comunidades mapuche que si bien tienen varias décadas como asentamientos estables, son producto de la política de la Confederación. En los años 90 varios de estos 
poblados empezaron a sufrir los embates de empresas petroleras que reclamaban como propias tales tierras. Ante ello, sus moradores se ampararon en la Constitución Nacional reformada en 1994 y en la Ley 23.302 para conseguir la titularidad de las tierras que ocupaban. En este proceso se conformó oficialmente en el año 2000 la comunidad Lonco Purrán, cercana a Cutral-Có. Quienes encabezaron las gestiones ante el Gobierno optaron por fundamentar los derechos indígenas recurriendo a la historia anterior a la "Conquista del Desierto", es decir, recordaron que esas eran las tierras de Feliciano Purrán. Si bien no todos sus pobladores "conocen" la historia de este cacique, estos -por consejo de los dirigentes mapuche citadinos-acordaron esa nominación. Así, la reivindicación territorial trajo consigo el reconocimiento étnico y paralelamente ciertas resignificaciones identitarias.

\section{Palabras finales}

En este trabajo planteamos que las expediciones militares iniciadas en la década de 1870 modificaron radicalmente las relaciones entre los Estados argentino y chileno y los indígenas que habitaban las tierras de Pampa, Patagonia y Araucanía. La "Conquista del Desierto", además de expresar la violencia interétnica del pasado, generó conflictos entre indígenas. En este sentido, los acontecimientos que demarcaron la lucha entre indigenas y argentinos durante 1878 -1885 nos permitieron deslindar dos procesos paralelos: uno, los proyectos de las "tribus" de Pampa y Norpatagonia en pos de unificar sus acciones de resistencia ante un enemigo común, las fuerzas nacionales. Y junto a ellos su contracara, es decir, las situaciones en las que cristalizaron las diferencias en la política de los indígenas de distintas regiones (mientras algunos buscaron resistir hasta el final otros prefieren pactar). Por su parte, advertimos que después de la derrota indígena, los cacicatos del "área arauco-pampeano-norpatagónica" perdieron su autonomía política y territorial a la vez que las identidades étnicas constituidas a lo largo del siglo XIX se redefinireron. Hacia 1895 las "tribus" de Namuncurá, de Luis Baigorria, de Sayhueque, de Curruhuin$\mathrm{ca}$, entre otros, habían sido relocalizadas; a su vez surgieron nuevos asentamientos en los que su componente poblacional no daba cuenta de las identidades políticas previas a la "Conquista del Desierto". Estos poblados emergieron de la mano de quienes habian "perdido todo" y "vagaban por el desierto". Consideramos entonces que en esta suerte de destinos múltiples luego de la "gran invasión" se asienta la ecléctica memoria histórica de quienes hoy actúan con fuerza política ante el Estado argentino. Las posiciones encontradas entre mapuche y ranqueles son expresión de este proceso.

\section{Referencias Bibliográficas}

BECHIS, Martha 1984, Interethnic relations during the period of Nation-State Formation in Chile and Argentina: from Sovereign to Ethnic. University Microfilms International. A bell \& Howell Information Company $300 \mathrm{~N}$. Zeeb Road. Ann Arbor. Michigan.

BECHIS, Martha 1999, "Los lideratos políticos en el área araucano-pampeana en el siglo XIX: ¿autoridad o poder?" En: "Etnohistoria" CD. Equipo NayA. Buenos Aires.

CALVO, Mayo 1990, Secretos y tradiciones mapuches. Editorial Andrés Bello. Chile.

DE JONG, Ingrid 2002, "Indio, nación y soberanía en la Cordillera Norpatagónica: fronteras de la inclusión y exclusión en el discurso de Manuel José Olascoaga". En: Nacuzzi, Lidia (comp.), Funcionarios, diplomáticos, guerreros. Miradas hacia el otro en las fronteras de pampa y patagonia (siglos XVIII y XIX). Buenos Aires: Sociedad Argentina de Antropología, 2002.

DELRÍO, Walther 2005, Memorias de expropiación. Sometimiento e incorporación indigena en la Patagonia. 1872 -1943. Universidad Nacional de Quilmes. Buenos Aires.

DURÁN, Guillermo 2004 Episodios en los territorios del sur (1879). Estanislao S. Zeballos. El elefante blanco. Buenos Aires.

DURÁN, Guillermo, 2006 Namuncurá y Zeballos. El archivo del cacicazgo de Salinas Grandes (1870-1880). Bouquet editores. UCA. Buenos Aires.

FERNÁNDEZ, César, 1999, Cuentan los mapuches. Ediciones nuevo siglo. Buenos Aires. 
FOERSTER, Rolf e Iván VERGARA 1996 "¿Relaciones interétnicas o relaciones fronterizas?": En: EXCERPTA N ${ }^{\circ} 5$ www.uchile.cl/facultades/csociales/excerpta/excerpta5/

JIMÉNEZ, Daniel y Francisco, 2006 "Acerca de los ranqueles. Los indígenas del Mamil Mapu y del Leu Mapu (1750-1840)". En: Primer encuentro entre Investigadores y Pueblos Originarios del Centro de Argentina. Santa Rosa, La Pampa.

KALINSKY, Beatriz y Osvaldo CAÑETE $2000 \mathrm{He}$ chos escritos con fuego. Las formas violentas de las relaciones sociales en la zona de frontera en el sur de Neuquén. Colección Argentina Indigena. Editorial Plus Ultra. Buenos Aires.

LEÓN SOLís, Leonardo 1982 "La corona española y las guerras intestinas entre los indígenas de "Araucania, Patagonia y las Pampas, 1760-1806". En: Nueva Historia, Revista de Historia de Chile. Año $2 \mathrm{~N}^{\circ} 5$. Asociación de Historiadores Chilenos (U.K.). Londres. pp. 31-67.

MANDRINI, Raúl 1984 Los araucanos de las pampas en el siglo XIX. Centro Editor de América Latina. Buenos Aires.

MANDRINI, Raúl y Sara ORTELLI 1993, Volver al país de los araucanos. Sudamericana. Buenos Aires.

MASES, Enrique 2002, Estado y cuestión indigena. El destino final de los indios sometidos en el sur del territorio (1878-1910). Prometeo Libros. Entrepasados. Buenos Aires.

NACUZZI, L. (comp.) Funcionarios, diplomáticos y guerreros. Miradas hacia el otro en las fronteras de pampa y patagonia (siglos $X V I I I$ y XIX). Publicaciones de la SAA. Buenos Aires.

NAVARRO FLORIA, Pedro, 2005 "La conquista de la memoria. La historiografía sobre la frontera sur argentina durante el siglo XIX". En: Universum. Revista de Humanidades y Ciencias Sociales. Año 20. Vol. 1. Universidad de Talca. Talca, Chile. pp. 89-111.

PALERMO, M. 1986, "Reflexiones sobre el llamado 'complejo ecuestre' en la Argentina". En: Runa. XVI.
PÉREZ ZAVALA, Graciana y Marcela TAMAGNINI 2005 "Los mapuche y la reconstrucción de su historia". En: VII Corredor das Idéias do Cone Sul. "Cone Sul: fronteiras, democracias, cidadanias, identidades". Universidade do Vale do Rio dos Sinos - UNISINOS, São Leopoldo - RS - Brasil. En Prensa.

PINTO RODRÍGUEZ, Jorge 1996 "Integración y desintegración de un espacio fronterizo. La Araucania y las Pampas, 1550-1990". En: PINTO, J. (ed.) Araucanía y Pampas, un mundo fronterizo en América del Sur. Ediciones Universidad de la Frontera. Temuco, Chile. pp. 11-46.

RATTO, Silvia 1994 "Indios amigos e indios aliados. Orígenes del "Negocio Pacífico" en la Provincia de Buenos Aires (1829-1832)". En: Cuadernos del Instituto Ravignani 5. Facultad de Filosofía y Letras. UBA. Buenos Aires.

ROCCHIETTI, Ana María 1998 "Cultura e identidad en los Andes". En: Revista del Centro de Investigaciones precolombinas. Año $1, \mathrm{~N}^{\circ} 1$. Instituto Joaquín V. González. Buenos Aires.

TAMAGNINI, Marcela 1995 Cartas de Frontera. Los documentos del conflicto interétnico. Universidad Nacional de Río Cuarto. Río Cuarto.

TAMGANINI, Marcela y Graciana PÉREZ ZAVALA 2004 "Las tribus ranqueles frente a los tratados de paz de la segunda mitad del siglo XIX: de las alianzas al conflicto". En: XV Congreso Nacional de Arqueología Argentina. Arqueologia e Integración Conceptual. Fronteras del Conocimiento". Universidad Nacional de Río Cuarto. Río Cuarto. CD.

VARELA, Gladys y Carla MANARA 2006 "Feliciano Purrán. El señor de los Andes". En: MANDRINI, R. (editor) Vivir entre dos mundos. Las fronteras del sur de la Argentina. Siglo XVIII y XIX. Nueva dimensión Argentina. Taurus. Buenos Aires. pp. 259-288.

VEZUB, Julio 2006 "Don Valentín Sayhueque. EL Gobernador indigena de las Manzanas". En: MANDRINI, R. (editor) Vivir entre dos mundos. Las fronteras del sur de la Argentina. Siglo XVIII y XIX. Nueva dimensión Argentina. Taurus. Buenos Aires. pp. 289-318.

WALTHER, Juan Carlos, 1980 La Conquista del Desierto. Eudeba. Buenos Aires. 